\title{
The effects of stimulus luminance and duration on iconic encodability
}

\author{
JAMES DYKES and GARVIN CHASTAIN \\ University of Texas, Austin, Texas 78712
}

\begin{abstract}
Stimulus luminance, stimulus duration, and pre- and postfield luminance were varied in a whole eport paradigm. Preformance in all conditions improved with longer durations. With pre- and postfield luminance equal to stimulus luminance, stimulus duration affected performance, but stimulus luminance did not. However, when pre- and postfield luminance was held constant, performance exhibited reciprocity between stimulus luminance and duration according to Bloch's Law.
\end{abstract}

Many experiments converge to demonstrate the existence of the icon, a high-capacity, rapidly decaying sensory store. Further, there is evidence that in order to be reported, information must be encoded from the icon into a short-term memory before the icon has decayed. If changes in stimulus luminance and stimulus duration affect performance, the changes in performance could be due either to changes in the duration of the icon or to changes in the encodability of the icon (how fast information can be encoded out of the icon). Kahneman (Kahneman, 1964; Kahneman \& Norman, 1964) has shown that, below a critical duration, luminance summates over time and that performance on an identification task is a function of the total energy of the stimulus (Bloch's Law). Similarly, Eriksen (Eriksen \& Hoffman, 1963) has shown that the stimulus and a light mask are integrated if they both occur within an interval of about $100 \mathrm{msec}$. Performance is a function of the contrast ratio of the integrated figure. The luminance of the masking field sums with the luminance of both the stimulus figure and background, and an integrated contrast ratio is applicable (the luminance summation/ contrast reduction hypothesis). Neisser (1967) suggested that increases in stimulus luminance and duration should increase iconic persistence. Thus, iconic duration (stimulus duration plus iconic persistence after stimulus offset) should increase with increases in stimulus duration. However, Haber and Standing (1970) found that iconic duration was a constant across increases in stimulus duration as long as luminance of the pre-and postfield was held constant and the duration of the stimulus did not exceed the constant iconic duration. They did find that the luminance of the pre-and postfields affected iconic duration. Iconic duration was $400 \mathrm{msec}$ if the masking fields were dark (no-mask condition) and $200 \mathrm{msec}$ if they were light (masking condition).

Requests for reprints should be sent to James Dykes, College of Humanities and Social Sciences, Division of Social Sciences, University of Texas at San Antonio, San Antonio, Texas 78285. C. A. Burnham and K. Gummerman read the first draft of the manuscript. Kent Gummerman sponsors this paper and takes full editorial responsibility for its content.
Haber and Standing's results can be reconciled with Kahneman's by assuming that iconic duration is affected by pre- and postfield luminance and that increases in stimulus luminance and duration result in a more legible icon (one from which it is easier or faster to encode information).

Two sets of data are consistent with this notion. Gough, Gummerman, and Dykes (in preparation) showed that, in a partial report paradigm, the icon's duration is independent of stimulus duration over the range of 40 to $120 \mathrm{msec}$. Consistent with duration affecting encodability, Mackworth (1963) found that with pre- and postfield luminance much brighter than the stimulus field ( 39 and $3.2 \mathrm{fL}$, respectively), performance in a whole report task increased with increasing stimulus duration over the range of 27 to $125 \mathrm{msec}$.

On the other hand, Sperling (1960) obtained data inconsistent with this idea. He found that in a whole report paradigm, performance was better when the preand postfield were dark (4.3 letters) than when the postfield was light (2.7 letters). This is consistent with iconic duration being shorter in the light masking condition. However, he found that performance did not improve in either condition when stimulus duration was increased from 15 to 50 msec. This would imply that there are different performance ceilings, depending upon the luminance of the masking field, and that stimulus duration has no effect on iconic encodability. However, Sperling's results could be due to differential practice. His subjects had had considerable practice with the dark pre- and postfield condition before they encountered the light postfield condition.

From Haber and Standing's (1970) results, it was assumed that iconic duration is a function of pre- and postfield luminance. This experiment tested a system in which increases in stimulus luminance and duration led to a more encodable icon and for which there was a single performance ceiling. For this experiment, pre- and postfield luminance, stimulus luminance, and stimulus duration were varied. The predictions were: (a) Increasing stimulus duration would lead to better performance (due to increased iconic encodability), 


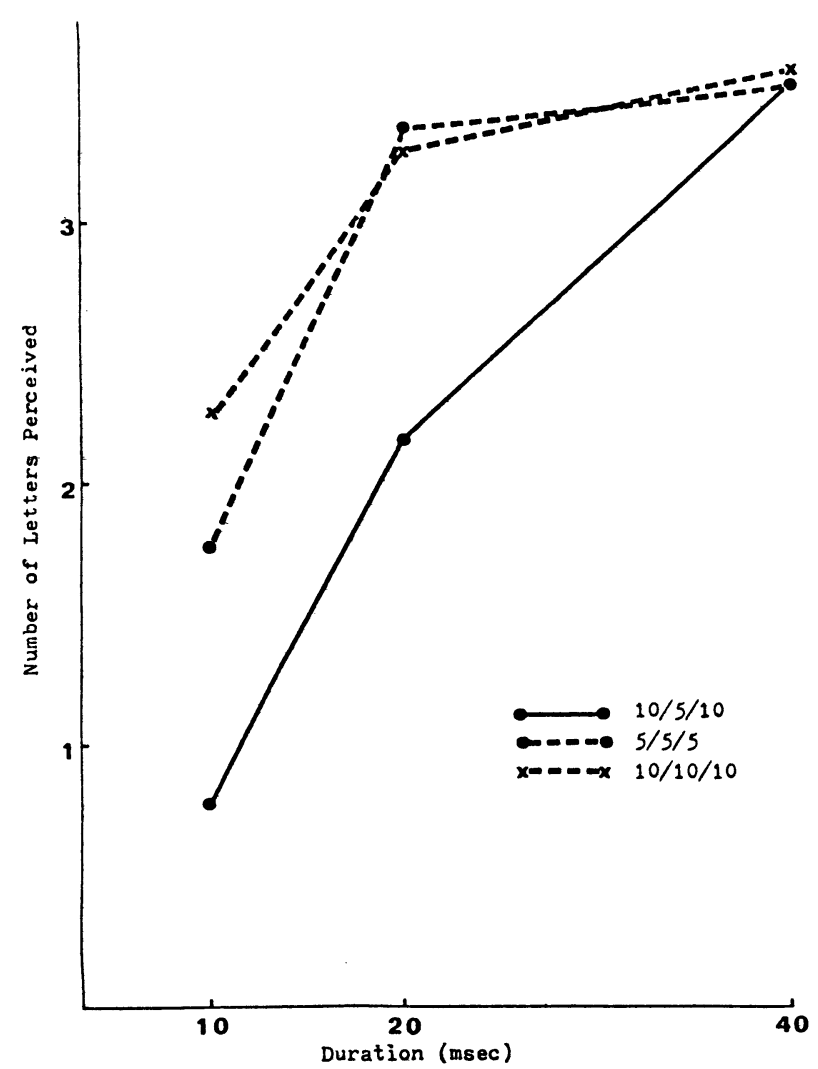

Figure 1. Mean number of letters perceived per trial for each of the three luminance conditions at each of the three durations tested.

(b) performance for any given duration would be the same (according to Eriksen's model), and (c) if pre- and postfield luminance was held constant, stimulus luminance and duration would exhibit reciprocity (according to Bloch's Law).

\section{METHOD}

\section{Subjects}

The subjects were nine upperclass undergraduate students (six male and three female) in an experimental methods course designed for potential graduate students in psychology.

\section{Stimuli and Apparatus}

The stimuli were 99 slides, each composed of 12 consonants arranged in three rows of four consonants each. Each slide was constructed by selecting letters randomly and without replacement from the set of 20 consonants (the letter $Y$ was excluded). The slides were high-contrast positive transparencies of typed black capital letters (IBM type style Prestige Elite 72). The consonants subtended about $35 \times 35 \mathrm{~min}$ visual angle, the space between letters in a row subtended about $35 \mathrm{~min}$, and the space between each of the three rows subtended $24 \mathrm{~min}$.

The stimuli were transilluminated in a three-field monocular tachistoscope (Scientific Prototype Autotach) at a viewing distance of $41.3 \mathrm{~cm}$. Stimulus duration was 10,20 , or $40 \mathrm{msec}$. Luminances were reduced and varied by means of Kodak neutral-density gelatin filters and were measured by a Spectra brightness spot meter. There were three combinations of stimulus luminance and pre- and postfield luminance. In two conditions prefield, stimulus, and postfield luminance were equal, the luminance being $5 \mathrm{fL}$ in one and $10 \mathrm{fL}$ in the other (subsequently referred to as $5 / 5 / 5$ and $10 / 10 / 10$, respectively). In the third condition the stimulus luminance was $5 \mathrm{fL}$ and the preand postfield luminances were $10 \mathrm{fL}(10 / 5 / 10)$.

\section{Procedure}

All subjects were run in a single session averaging about $75 \mathrm{~min}$ in length. Luminance condition $(5 / 5 / 5,10 / 5 / 10$, and $10 / 10 / 10)$ was constant within a block. A block consisted of 18 practice trials (6 at each duration) and 81 test trials $(27$ at each duration). The order of luminance conditions was counterbalanced using a 3 by 3 Latin square with three replications of each order. In Blocks 1 and 3 the practice and the test trials were presented in forward order, while they were presented in reverse order in Block 2.

At the beginning of the session, the subject was fully informed about the nature of the stimulus displays. Whenever a subject reported the same consonant twice in the same display or reported a vowel, the erroneous response was not recorded and the subject was reminded of the nature of the stimuli. The subject was instructed to fixate a central dot before each trial.

The subjects were instructed to free recall as many letters as possible and not to be overly concerned about occasionally reporting a letter not present in the array. They were informed that their correct reports would be adjusted in terms of their false reports. After the 18 practice trials of the first block, the subject was told to be less cautious in responding if he had made no mistakes; if he had made over six errors, he was told to be more cautious. The subject was never again given feedback concerning his criterion. Subjects were further instructed to report the letters in any order they wished. A reported letter was scored correct if it appeared anywhere in the array. The subject was not informed of the nature of the luminance conditions until after the experiment.

\section{RESULTS}

The mean number of consonants perceived over trials was computed for each subject using a correction for guessing formula. ${ }^{1}$ The means over subjects are shown in Figure 1.

An analysis of variance was run on the subjects' mean number perceived per trial using a 3 (Luminance Conditions) by 3 (Durations) by 9 (Subjects) design. The Luminance Condition effect, Duration effect, and Luminance Condition by Duration interaction were all significant at the .01 level $(F=6.39, \mathrm{df}=2 / 16$; $\mathrm{F}=29.73, \mathrm{df}=2 / 16 ; \mathrm{F}=5.11, \mathrm{df}=4 / 32$, respectively). The source of the interaction was investigated by considering each luminance condition and stimulus duration combination a separate condition. An overall analysis and subsequent individual comparisons were performed. The overall conditions effect was significant $(F=14.40, d f=8 / 64, p<.01)$. Performance in $10 / 5 / 10$ at $10 \mathrm{msec}$ was the poorest $(\mathrm{F}=60.21$, df $=1 / 64$, $\mathrm{p}<.01)$. Performance was similar for $10 / 5 / 10$ at $20 \mathrm{msec}$ and $5 / 5 / 5$ and $10 / 10 / 10$ at $10 \mathrm{msec}(\mathrm{F}<1)$. Performance for these three conditions was poorer than for $10 / 5 / 10$ at $40 \mathrm{msec}$ and $5 / 5 / 5$ and $10 / 10 / 10$ at $20 \mathrm{msec}(\mathrm{F}=37.66, \mathrm{df}=1 / 64, \mathrm{p}<.01)$. As predicted, these last three conditions did not differ from each other $(\mathrm{F}<1)$. Contrary to our predictions, performance for $5 / 5 / 5$ and $10 / 10 / 10$ at $20 \mathrm{msec}$ and $10 / 5 / 10$ at 
$40 \mathrm{msec}$ was not significantly poorer than for $5 / 5 / 5$ and $10 / 10 / 10$ at $40 \mathrm{msec}(\mathrm{F}<1)$. This seems to be due to a ceiling effect (about 3.5 letters for these subjects).

\section{DISCUSSION}

The most obvious result was the increase in performance with increased duration for all masking field conditions, which replicates the results Mackworth (1963) found with masking fields 12 times as bright as the stimulus field. The results suggest that when performance is below ceiling, increasing duration will increase performance, regardless of the luminance of the pre- and postfield. The negative acceleration of the duration effect can be explained as a ceiling effect for at least some subjects on some trials. Further, a single performance ceiling was evident. The difference between these results and Sperling's (1960) could be due to the fact that Sperling's subjects had more practice in the dark pre- and postfield condition than in the masking condition, while order of luminance conditions was counterbalanced in the current experiment. It is also possible that the difference is a result of Sperling's requiring correct positional information for a correct response, while we did not.

Performance in the $5 / 5 / 5$ condition was similar to performance in the $10 / 10 / 10$ condition at all durations. This is compatible with the luminance summation/contrast reduction hypothesis of Eriksen and Hoffman (1963). Since the contrast ratios of the integrated stimuli in these two conditions are the same, performance should be equal.

Performance in the $10 / 5 / 10$ condition was compared with that in the $10 / 10 / 10$ condition to test reciprocity of stimulus luminance and duration in iconic readability when masking field luminance is held constant. Reciprocity predicts that performance for $10 / 10 / 10$ at $10 \mathrm{msec}$ should equal performance for $10 / 5 / 10$ at $20 \mathrm{msec}$ and that performance for $10 / 10 / 10$ at $20 \mathrm{msec}$ should equal performance for $10 / 5 / 10$ at $40 \mathrm{msec}$. The analysis showed no difference for these comparisons. Thus Bloch's Law was found to hold in a light pre- and postfield condition only when masking field luminance was held constant.

The model posited in the current study is one in which stimulus duration and luminance determine iconic encodability. The results of the investigation indicated that, below short-term memory capacity (the performance ceiling), performance improves with increased stimulus durations. Doubling the stimulus luminance is offset by doubling the luminance of the masking fields. However, if masking field luminance is held constant, stimulus luminance and duration exhibit reciprocity in determining performance. The force of this conclusion must be tempered by the fact that only two comparisons were involved, with one of the comparisons possibly constrained by ceiling effects. The data are nevertheless highly suggestive, and further investigations of Bloch's Law appear warranted. Future investigations should test reciprocity using several durations in the 5- to $40-\mathrm{msec}$ range and several stimulus luminances.

\section{REFERENCES}

Eriksen, C. W., \& Hoffman, M. Form recognition at brief durations as a function of adapting field and interval between stimulations. Journal of Experimental Psychology, 1963, 66, 485-499.

Haber, R. N., \& Standing, L. G. Direct estimates of the apparent duration of a flash. Canadian Journal of Psychology, 1970, 24, 216-229.

KaHNEman, D. Temporal summation in an acuity task at different energy levels - a study of the determinates of summation. Vision Research, 1964, 4, 557-566.

Kahneman, D., \& Norman, J. The time-intensity relation in visual perception as a function of observer's task. Journal of Experimental Psychology, 1964, 68, 215-220.

MACKWORTH, J. F. The duration of the visual image. Canadian Journal of Psychology, 1963, 17, 62-81.

NeISSER, U. Cognitive psychology. New York: Appleton-CenturyCrofts, 1967.

SPERLING, G. The information available in brief presentations. Psychological Monographs, 1960, 74 (11, Whole No. 498).

\section{NOTE}

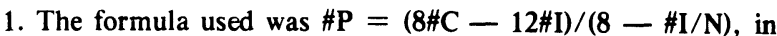
which \#P is number of letters perceived, \#C is number of letters correctly reported, \#I is number of letters incorrectly reported, and $\mathrm{N}$ is number of trials. The probability of a correct guess changes as letters are perceived, because stimulus letters within a matrix were chosen without replacement. This correction for guessing formula takes this sequential change in probability into account for our stimuli.

(Received for publication June 21, 1976.) 